\title{
Metabotropic glutamate receptor agonists for schizophrenia
}

Paul J. Harrison

\section{Summary}

A drug acting at metabotropic glutamate receptors has recently been reported to be an effective antipsychotic, breaking the rule that only dopamine receptor-blocking drugs have this property. The finding complements accumulating evidence that glutamatergic abnormalities are important in the pathophysiology of schizophrenia.

\section{Declaration of interest}

I have received honoraria from various pharmaceutical companies, including Lilly (who funded the trial discussed here), for giving non-promotional lectures, chairing scientific meetings or for consultancy work. I hold an unrestricted research grant from GlaxoSmithKline.
Paul J Harrison is a Professor of Psychiatry in Oxford. He trained in Oxford and London and his research focuses on the molecular neurobiology of psychosis.

\section{Introduction}

Without exception, existing antipsychotics work via dopamine $\mathrm{D}_{2}$ receptors. Although variation in affinity and actions at several monoamine receptors contributes to the differing profiles of individual drugs, all attempts to make an effective non-dopaminergic antipsychotic have failed. ${ }^{1}$ This has been a frustrating state of affairs given the many limitations of the current drugs - lack of efficacy in some patients, side-effects in many, and no meaningful effects against the negative and cognitive symptoms of schizophrenia. Now the situation appears to have changed, with a proof-of-concept double-blind randomised clinical trial reporting antipsychotic efficacy of a group II metabotropic glutamate receptor agonist. ${ }^{2}$ The compound tested, LY2140023, is a pro-drug, metabolised to the active compound LY404039 and used because the latter has a low oral bioavailability. LY404039 is a highly selective agonist at group II metabotropic glutamate receptors (comprised of mGluR2 and mGluR3), with no significant affinity for any other receptors, including dopamine receptors., ${ }^{2,3}$

\section{Methods and results}

Patil and colleagues ${ }^{2}$ randomised 196 participants with chronic schizophrenia to LY2140023 (80 mg per day), placebo, or olanzapine (15 mg per day), in a 3:2:1 ratio. The trial was conducted in Russia by Lilly. It lasted 4 weeks and used two standard outcome measures: the Positive and Negative Syndrome Scale (PANSS) and the Clinical Global Impression - Severity (CGI-S) scale. At baseline, patients averaged 95 on the PANSS and 4.9 on the CGI-S, indicative of quite severe psychopathology. Existing medication was tapered off over 3-9 days and, after a 1-day placebo lead-in, treatment was initiated. The mean change on the PANSS was -13.2 with LY2140023, -19.1 with olanzapine and +7.6 with placebo. The improvement was spread across positive and negative symptom subscales, with LY2140023 and olanzapine showing a similar profile and time course. The CGI-S decreased by 0.62 on LY2140023 and by 0.89 on olanzapine, but increased by 0.35 on placebo. In terms of categorical response (a $25 \%$ reduction in PANSS score), 32\% of participants responded to LY2140023, compared with $3 \%$ with placebo and $41 \%$ with olanzapine. LY2140023 did not produce extrapyramidal side-effects, weight gain, or raised prolactin - three troublesome properties of many other antipsychotics. The only emergent adverse event more common in the LY2140023 group was 'affect lability', seen in $12 \%$ of participants.

\section{Discussion}

The results suggest that LY2140023 is an effective and welltolerated antipsychotic and, given its distinct pharmacology, appears to represent a major breakthrough in the drug treatment of psychosis. However, it is important not to get carried away. Independent replication of the findings is, of course, essential. Trials will be required that are larger and longer, that include other groups such as those with first-episode illness, that include combination therapy with other antipsychotics, and that measure additional outcomes including quality of life and cognition. In future work, several issues need to be addressed. First, although LY2140023 did not separate statistically from olanzapine, the magnitude of response to the new drug was lower and the discontinuation rate higher: $34 \%$ v. $21 \%$ on olanzapine, with lack of efficacy being the reason in $15 \%$ of patients on LY2140023, compared with $6 \%$ on olanzapine. A dose-ranging study is needed to discover whether higher doses of LY2140023 enhance its efficacy. Even if group II metabotropic glutamate receptor agonists were to prove somewhat less efficacious than existing antipsychotics, they could still be valuable if they produce fewer side-effects or have benefits in particular subgroups; for example, their anxiolytic properties ${ }^{4}$ may be useful. Second, as with all agonists, there is the concern that the response might attenuate with time due to receptor down-regulation; however, there was no hint of this occurring by the end of the trial. Third, the 'affect lability' requires investigation; it might be a useful property if it denotes an improvement in affective flattening, but it might also be detrimental if it indicates an instability of affect.

Group II metabotropic glutamate receptors are autoreceptors that inhibit release of glutamate and regulate other neurotransmitters. ${ }^{5}$ They have been implicated in schizophrenia ${ }^{6,7}$ as part of a broader glutamate involvement in its pathophysiology. ${ }^{8-10}$ Trials with other glutamatergic agents, mainly positive modulators of $N$-methyl-D-aspartic acid receptors, have also suggested some efficacy, ${ }^{10,11}$ although generally as adjuncts to existing antipsychotics and with inconclusive results overall. ${ }^{12}$ One problem has been that it is not clear exactly what the nature of the glutamate abnormality is in schizophrenia, nor, therefore, what kind of glutamatergic drug might be beneficial. The present results imply, simplistically, that inhibition of glutamate release and thence 'damping down' of glutamate transmission is therapeutic. 
However, the story is likely to be far more complicated than this, in terms of the underlying abnormality as well as the molecular and synaptic mechanisms by which LY2140023 works. As part of this investigation, the relative contribution made by mGluR2 and mGluR3 needs to be clarified, as there are significant functional differences between these receptors. ${ }^{7}$ In addition, even though LY2140023 may be the first antipsychotic not to act through dopamine receptors, its effects might ultimately be mediated, at least partly, via dopaminergic pathways, reflecting the many interactions between glutamatergic and dopaminergic transmission. ${ }^{8,9}$

Although preliminary, the findings of Patil and colleagues ${ }^{2}$ are welcome in a field craving a genuine pharmacotherapeutic advance, following increasing realisation of the shortcomings of current antipsychotics, both typical and atypical. The results will stimulate the search for new drugs that go beyond the limitations of targeting dopamine receptors, and will reaffirm the hope that more successful and tolerable treatments can be derived from the rapid progress being made in understanding the pathophysiology of schizophrenia. ${ }^{13}$ Finally, much of the interest in glutamate in schizophrenia, including group II metabotropic receptors, has been with regard to the cognitive symptoms. ${ }^{14}$ The finding that LY2140023 has antipsychotic properties is therefore something of a bonus. Equally, the real value of these drugs will arise if they prove also to improve cognitive functioning, a major unmet therapeutic need in schizophrenia.

Paul J. Harrison, MD, DM(Oxon), FRCPsych, Department of Psychiatry, Warneford Hospital, Oxford OX3 7JX, UK. Email: paul.harrison@psych.ox.ac.uk

First received 13 Sep 2007, final revision 13 Sep 2007, accepted 12 Oct 2007

\section{References}

1 Miyamoto S, Duncan GE, Marx CE, Lieberman JA. Treatments for schizophrenia: a critical review of pharmacology and mechanisms of action of antipsychotic drugs. Mol Psychiatry 2005; 10: 79-104.

2 Patil ST, Zhang L, Martenyi F, Lowe SL, Jackson KA, Andreev BV, Avedisova AS, Bardenstein LM, Gurovich IY, Morozova MA, Mosolov SN,
Neznanov NG, Reznik AM, Smulevich AB, Tochilov VA, Johnson BG, Monn JA, Schoepp DD. Activation of $\mathrm{mGlu2/3}$ receptors as a new approach to treat schizophrenia: a randomized Phase 2 clinical trial. Nature Med 2007; 13: 1102-7.

3 Rorick-Kehn LM, Johnson BG, Burkey JL, Wright RA, Calligaro DO, Marek GJ, Nisenbaum ES, Catlow JT, Kingston AE, Giera DD, Herin MF, Monn JA, McKinzie DL, Schoepp DD. Pharmacological and pharmacokinetic properties of a structurally novel, potent, and selective metabotropic glutamate $2 / 3$ receptor agonist: in vitro characterization of agonist (-)-(1R,4S,5S,6S)-4amino-2-sulfonylbicyclo[3.1.0]hexane-4,6-dicarboxylic acid (LY404039). J Pharmacol Exp Ther 2007; 321: 308-17.

4 Palucha A, Pilc A. Metabotropic glutamate receptor ligands as possible anxiolytic and antidepressant drugs. Pharmacol Ther 2007; 115 116-47.

5 Spooren W, Ballard T, Gasparini F, Amalric M, Mutel V, Schreiber R. Insight into the function of Group I and Group II metabotropic glutamate (mGlu) receptors: behavioural characterization and implications for the treatment of CNS disorders. Behav Pharmacol 2003; 14: 257-77.

6 Egan MF, Straub RE, Goldberg TE, Yakub I, Callicott JH, Hariri AR, Mattay VS, Bertolino A, Hyde TM, Shannon-Weickert C, Akil M, Crook J, Vakkalanka RK, Balkissoon R, Gibbs RA, Kleinman JE, Weinberger DR. Variation in GRM3 affects cognition, prefrontal glutamate, and risk for schizophrenia. Proc Natl Acad Sci USA 2004; 101: 12604-9.

7 Harrison PJ, Lyon L, Sartorius LJ, Burnet PWJ, Lane TA. The group II metabotropic glutamate receptor 3 (mGluR3, mGlu3, GRM3): expression, function, and involvement in schizophrenia. J Psychopharmacol 2008. In press.

8 Konradi C, Heckers S. Molecular aspects of glutamate dysregulation: implications for schizophrenia and its treatment. Pharmacol Ther 2004; 97 : 153-79.

9 Harrison PJ, Weinberger DR. Schizophrenia genes, gene expression, and neuropathology: on the matter of their convergence. $\mathrm{Mol}$ Psychiatry 2005; 10: $40-68$.

10 Goff DC, Coyle JT. The emerging role of glutamate in the pathophysiology of schizophrenia. Am J Psychiatry 2001; 158: 1367-77.

11 Javitt DC. Glutamate as a therapeutic target in psychiatric disorders. $\mathrm{Mol}$ Psychiatry 2004; 9: 984-97.

12 Tuominen HJ, Tiihonen J, Wahlbeck K. Glutamatergic drugs for schizophrenia: a systematic review and meta-analysis. Schizophr Res 2005; 72: 225-34.

13 Gray JA, Roth BL. The pipeline and future of drug development in schizophrenia. Mol Psychiatry 2007; 12: 904-22.

14 Moghaddam B. Targeting metabotropic glutamate receptors for treatment of the cognitive symptoms of schizophrenia. Psychopharmacol 2004; 174: 39-44. 